\title{
Problem drinking among young people in Ireland
}

\author{
Nnamdi Nkire ${ }^{1}$ and Izu Nwachukwu ${ }^{2}$
}

\begin{abstract}
${ }^{1}$ Clinical Research Fellow, St Davnet's Hospital, Cavan/Monaghan Mental Health Service, Co. Monaghan, Ireland ${ }^{2}$ Senior Registrar, St Vincent's University Hospital, and Special Lecturer in Psychiatry, Department of Medicine and Medical Sciences, University College Dublin, Ireland, email izunwachukwu@hotmail.com
\end{abstract}

$\Lambda$ Icohol is widely consumed in many societies. It is estimated to be responsible for $4 \%$ of the global disease burden, and is third only to tobacco and hypertension as a leading cause of death in high-income countries. Ireland has one of the highest levels of alcohol use per capita in the world. According to Barnardos (a children's charity) there was a $48 \%$ increase in alcohol consumption per capita in Ireland between 1986 and 2006 (Barnardos, 2008). The Irish government endorsed the European Charter on Alcohol in 1995 but, in spite of this, the negative health consequences of alcohol consumption have increased (Mongan et al, 2002). About $28 \%$ of all injuries presenting to emergency departments in Ireland are alcohol related (Hope, 2008) and the number of hospital discharges related to alcohol increased by $92 \%$ between 1995 and 2002 (Mongan et al, 2002). Hope (2008) found that alcohol was implicated in $36.5 \%$ of road traffic fatalities in 2003 in Ireland, and was also a contributory factor in several cases of house fires and domestic abuse.

The average age of drink initiation in Ireland is 13 and continues to fall (Palmer \& O'Reilly, 2008). The European School Survey Project on Alcohol and Other Drugs (ESPAD) revealed that Irish 16-year-olds are among the highest misusers of alcohol in Europe in terms of binge drinking and drunkenness (Hibell et al, 2004). Irish adolescents spend approximately $€ 145$ million annually on alcohol (Office of Tobacco Control, 2006), with $25 \%$ of Irish schoolchildren surveyed admitting to getting drunk regularly. This was double the rate reported by Polish children and five times that of French children (Hibell et al, 2004)

In this paper, we examine the factors that may influence the attitudes of young people in Ireland to problem drinking.

\section{Overview of youth-oriented alcohol-related policies in Ireland}

A National Alcohol Policy (NAP) was adopted by the government in 1996 to address the widespread problem of alcohol misuse in Ireland. In 2002 the Strategic Task Force on Alcohol (STFA) took particular interest in the effects on young people of excessive drinking. It made recommendations aimed at lessening the impact of alcohol advertising. It advocated monitoring of the content, placement and timing of advertisements to ensure that they do not appeal to or target children. It also called for a ban on the drinks industry from sponsoring children's activities. The Commission on Liquor Licensing, established in 2003, further recommended the promotion of school-based educational measures as a means of decreasing alcohol-related problems. Other policy measures that were adopted by the state included setting the legal age for purchasing alcohol at 18 years, introduction of a national identity card system as proof of age for purchasing alcohol and random breath testing of drivers, with particular emphasis on young people.

\section{Young people and their attitudes to alcohol use in Ireland}

In 2007, the Office of the Minister for Children (OMC) organised a youth-led and youth-friendly consultation process aimed at providing a safe atmosphere in which young people could freely express their opinions regarding alcohol misuse among youths, and give their views on more effective ways of dealing with this problem. About 257 youths aged 12-18 years attended these forums in five locations across the country. The problem of excessive teenage drinking was acknowledged by all groups. Participants were of the view that scare-mongering educational tactics to persuade young people not to drink at all are unrealistic, and preferred an emphasis on 'reasonable drinking'. They also believed that young people who drink reasonably should be used as role models for younger people, rather than using only those who never drink. The top five solutions proffered by the youths for curbing the effects of under-age drinking were:

o lowering the legal age of drinking alcohol to 16

o providing alternative, alcohol-free facilities for young people

o promoting and supporting the role of parents

O developing age-appropriate and specialist-delivered educational programmes

o updating and enforcing the national identity card system and other related laws for the purchase of alcohol.

Participants also identified the roles of the police, media, peer pressure and peer mentoring as important. These 'solutions' are likely to reflect the factors that greatly influence the attitudes of Irish youths to alcohol misuse.

It has been suggested that, in the UK, young people drink alcohol for different reasons, related to their ages (Newburn \& Shiner, 2001): 12- to 13-year-olds experiment with alcohol from a desire to attain adult status; 14- to 15-year-olds drink to get drunk, with the aim of testing their limits and having fun; while 16- to 17-year-olds see drinking as a sign of maturity and experience. It is likely that this is similarly the case with Irish teenagers. 


\section{Factors contributing to problem drinking among Irish youths}

\section{Cost of alcohol}

The cost of alcohol is inversely linked with consumption rates and related problems among youths (Chaloupka et al, 2002). In Ireland, alcoholic drinks have become more affordable for youths, a situation which may have been worsened by a reduction in the excise duty on alcohol in the December 2009 budget.

\section{Regulation of advertising}

Studies have consistently demonstrated a positive correlation between exposure to alcohol advertising and the level of alcohol use (Smith \& Foxcroft, 2007); this link has also been demonstrated in children (Dring \& Hope, 2001). The voluntary code for alcohol advertising as currently practised in Ireland does not maximise the potential to reduce consumption.

\section{Legal age for purchasing alcohol}

The legal age for purchasing alcohol in Ireland is 18. In the USA it is 21. This difference may explain, at least in part, why only $7 \%$ of American teenagers get drunk regularly, compared with $25 \%$ of teenagers in Ireland. Although a national identity card was introduced in Ireland in 1999 to serve as proof of age for alcohol purchase, inadequate enforcement means this has had little effect on the procurement of alcohol by under-age drinkers.

\section{Normalisation of unhealthy drinking practices and attitudes}

The concept of modelling is central to social learning theory. Unhealthy drinking patterns and behaviours and their attendant consequences enjoy high tolerance in Irish culture, to the point of normalisation (Mongan et al, 2002). Social influences (e.g. parents and peers) are among the strongest correlates of adolescent substance misuse (Hawkins et al, 1992). Attitudes of Irish youths to alcohol are likely to be formed through these social influences (Abrams \& Niaura, 1987).

\section{Stakeholders and their roles}

\section{Government}

The government has a role in providing the political will necessary to address the problems of youth drinking. Alcohol policies in Ireland, when benchmarked against those of other members of the European Union (EU), are rather casual (Anderson \& Baumberg, 2006). The recent postponement of the lowering of the legal blood alcohol concentration limits for driving (from $80 \mathrm{mg}$ to $50 \mathrm{mg}$ of alcohol per $100 \mathrm{ml}$ of blood, in line with most EU countries) following opposition from vested interest groups illustrates this casual approach.

\section{The alcohol industry}

Teenagers who drink regularly are more likely to become heavy-drinking adults (Grant et al, 2006). Early brand loyalty is established through brand awareness and exposure. According to Smyth et al (2008), the industry has lobbied against the introduction of stricter advertising guidelines with this in mind. In June 2009, the director of the Alcohol
Beverage Federation of Ireland rejected calls for new legislation to govern drinks advertising on television.

\section{Media organisations}

Alcohol advertising generated about $€ 69$ million in 2007, a 31\% increase from 2006 figures (Smyth et al, 2008). It is likely that editorial policies are influenced by such profits.

\section{Conclusion}

Binge drinking and drunkenness among young people in Ireland are common and place a burden on society. The attitude of young people to alcohol use is influenced by government policies (which determine accessibility and affordability) as well as social and cultural factors. The governmental and other stakeholders therefore have a role in ensuring that the appropriate policies are enacted and properly enforced, and that sociocultural mediators are modified to promote a positive change in the attitude of young people to alcohol.

\section{References}

Abrams, D. B. \& Niaura, R. S. (1987) Social learning theory. In Psychological Theories of Drinking and Alcoholism (eds H. T. Blane \& K. E. Leonard), pp. 131-178. Guilford Press.

Anderson, P. \& Baumberg, B. (2006) Alcohol in Europe: A Public Health Perspective. Institute of Alcohol Studies.

Barnardos (2008) Submission to the Alcohol Advisory Group, http:// www.barnardos.ie/assets/files/pdfs/submission_to_the_Advisory Group.pdf (accessed 23 August 2010).

Chaloupka, F. J., Grossman, M. \& Saffer, H. (2002) The effects of price on alcohol consumption and alcohol-related problems. Alcohol Research and Health, 26, 22-34.

Dring, C. \& Hope, A. (2001) The Impact of Alcohol Advertising on Teenagers in Ireland. Health Promotion Unit, Department of Health and Children

Grant, J. D., Scherrer, J. F., Lynskey, M. T., et al (2006) Adolescent alcohol use is a risk factor for adult alcohol and drug dependence: evidence from a twin design. Psychological Medicine, 36, 109-188.

Hawkins, J., Gtalano, R. \& Miller, J. (1992) Risk and protective factors for alcohol and other drug problems in adolescence and early childhood: implications for substance abuse prevention. Psychological Bulletin, 112, 64-105.

Hibell, B., Anderson, B., Bjarnason, T., et al (2004) The ESPAD Report, 2003. Swedish Council for Information on Alcohol and Other Drugs and Pomidou Group at the Council of Europe.

Hope, A. (2008) Alcohol Related Harm in Ireland. Health Services Executive, Alcohol Implementation Group.

Mongan, D., Reynolds, S., Fanagan, S., et al (2002) Health Related Consequences of Problem Alcohol Use. Overview 6. Health Research Board.

Newburn \& Shiner (2001) Cited in Alcohol Concern Factsheet. Young People's Drinking. March 2004. Available at http://www.alcoholconcern. org.uk/servlets/wrapper/knowledgebase.jsp?topic id $=5$ \&theme id $=84$ (accessed August 2010).

Office of Tobacco Control (2006) Children, Youth and Tobacco: Behaviour, Perceptions and Public Attitudes. Office of Tobacco Control.

Palmer, D. \& O'Reilly, G. (2008) Strategic Task Force on Alcohol: Second Report. Health Promotion Unit, Department of Health and Children.

Smith, L. \& Foxcroft, D. (2007) The Effect of Alcohol Advertising and Marketing on Drinking Behaviour in Young People: A Systematic Review. Alcohol Education and Research Council.

Smyth, B., Keenan, E., Flannery, W., et al (2008) Calling Time on Alcohol Advertising and Sponsorship in Ireland: Supporting a Ban on Alcohol Advertising in Ireland. Protecting Children and Adolescents. Policy paper by the Faculty of Addiction Psychiatry, Irish College of Psychiatrists. 